\title{
Benefits of Qualitative Simulation for Managing Fluctuating Staffing Needs
}

\author{
T. T. Nichols
}

June 2001 
INEEL/EXT-01-00898

\title{
Benefits of Qualitative Simulation for Managing Fluctuating Staffing Needs
}

\author{
Todd T. Nichols
}

June 2001

Idaho National Engineering and Environmental Laboratory High Level Waste Program Idaho Falls, Idaho 83415

Prepared for the

U.S. Department of Energy Assistant Secretary for Environmental Management Under DOE Idaho Operations Office Contract DE-AC07-99ID13727 


\begin{abstract}
Management of the High Level Waste Program Office at the Idaho National Environmental and Engineering Laboratory has projected oscillating future employment levels. A simple computer model was created to help convince management that qualitative modeling of "soft" variables can provide appreciable insight into the consequences and performance of alternative staffing policies. Advocacy of the model underlying the simulation or a particular strategy did not motivate the study, but rather a desire to instill enthusiasm and elicit new and improved conceptual models from management. Six qualitative and three quantitative generic insights to managing staffing levels are gained from the simulations. These insights in their generic form should be familiar to those knowledgeable of system dynamics or computer/instrument process control. Their potential usefulness to developing staffing strategies is stressed. The two primary overarching assertions that flow from the simulation results are: 1) the presence of multiple feedbacks, time delays, and continuous flows introduce instability into a personnel system that complicates the management of staffing levels. Many times "soft" variables, such as morale, productivity, and efficiency are the sources of such influences; and 2) such influences can be successfully modeled. In the case of the simple model used in these simulations, for example, the qualitative impact of a strategy using hiring and laying off as the sole managerial interventions is assessed.
\end{abstract}




\section{CONTENTS}

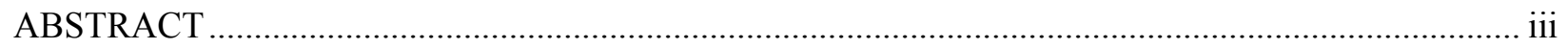

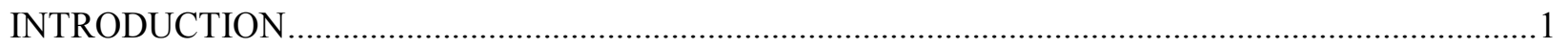

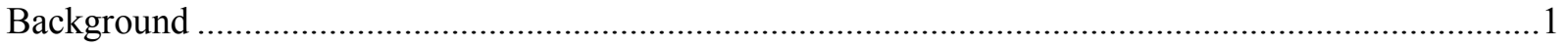

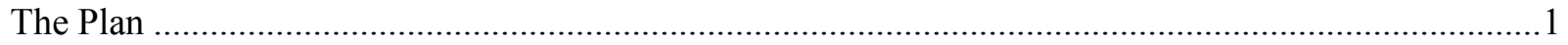

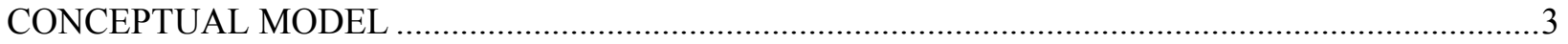

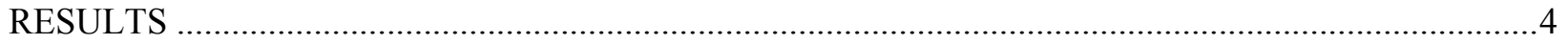

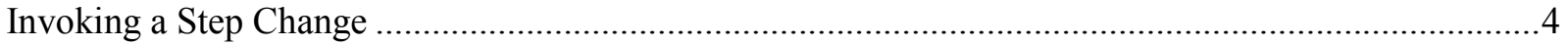

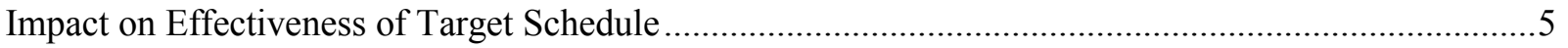

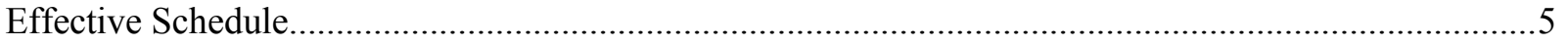

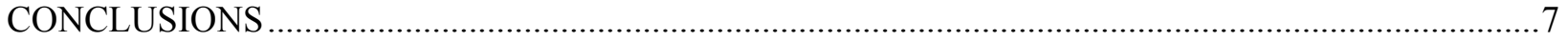

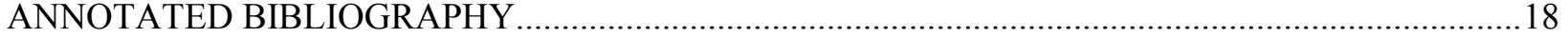

\section{FIGURES}

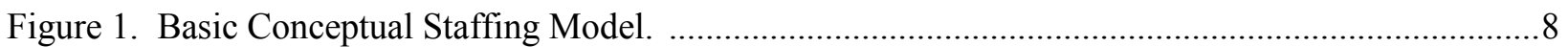

Figure 2. Response With No Feedback Added (Only Hiring \& Laying Off Used To Push Actual Towards

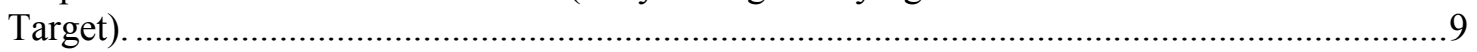

Figure 3. Response With Only Bureaucracy Feedback Added. .......................................................... 10

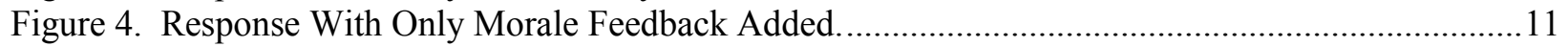

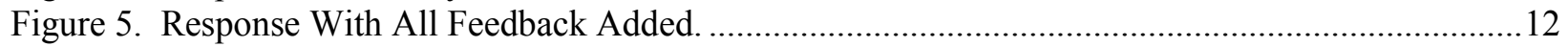

Figure 6. Response With All Feedback And Attrition (Downward Step Change)................................... 13

Figure 7. Response With All Feedback And Attrition (Upward Step Change). ...................................... 14

Figure 8. Target Decoupled From Productivity Feedback (Fluctuating Target) .......................................15

Figure 9. Modified Target To Account For Productivity Feedback.........................................................16

\section{TABLES}

Table 1. Summary Of Simulation Learning. 


\section{Benefits of Qualitative Simulation for Managing Fluctuating Staffing Needs}

\section{INTRODUCTION}

Management of the High Level Waste Program Office at the Idaho National Environmental and Engineering Laboratory has projected oscillating future employment levels due to shrinking budgets and the progression of various waste treatment projects through their life cycles.

\section{Background}

Tasked with treating and storing radioactive and hazardous waste, Program personnel have a strong engineering bent. In the past, the Program organization has favored quantitative analysis and frowned upon qualitative studies, especially when "soft" variables are involved. Trust and morale are examples of "soft" attributes included in past qualitative simulation attempts that were met with much disdain from management and other engineering personnel.

However, the makeup of the Program's management has changed appreciably since these failed attempts, and some of the new managers seem to be more open to the importance of "soft" variables in decision making. Consequently, it is felt that this problem regarding staffing policies offers an appropriate opportunity to once again propose qualitative analysis as a tool for strategic decision making to management.

\section{The Plan}

A multi-phase approach will be used to increase management's understanding of its perceived problem. The objectives of the first phase are to convince management of the importance of "soft" factors and the potential to qualitatively model their influence, and to obtain input to develop a conceptual model more representative of management's perspectives.

Advocacy of the model underlying the simulation is not the purpose of Phase I. Rather, the aim is advocacy of the hypothesis that hidden secondary effects of management actions can be important and can be satisfactorily modeled. Regardless of the intentions behind actions concerning personnel management, the actions can have secondary and rippling influences that both qualitatively and quantitatively affect a company's performance. Increasing management's acceptance of the utility of qualitative modeling to assess such phenomenon is the goal of this simulation effort.

Because advocacy of the conceptual model is not the objective, it is not necessary that the model match any one manager's personal mental model or to be comprehensive enough to envelope the ideas of the entire management team. There are three main requirements for the conceptual model in Phase I: 1) it must be logical so that it can be defensible; and 2) it must be simple enough to not distract from the primary focus on increasing management's awareness of qualitative analysis; and 3) it must be complex enough to have an appropriate mix of balancing, reinforcing, and continuous flows in order to clearly show the importance of "soft" factors and the utility of qualitative modeling. It is felt that the conceptual model described in the next section satisfies these three criteria.

Phase I will involve sitting down with a few key managers, one-on-one, to briefly discuss the conceptual model and to run various simulation scenarios that give insight into the staffing problem. The computer 
simulation was created in ithink from High Performance Systems, Inc. The goal of these meetings is not for the manager to say, "I agree with your conceptual model. This captures all the nuances of staffing." To the contrary, the goal is to have the manager say, for example, "This is a great tool! I think that layoffs have "such and such' effect, that new hires have 'such and such' effect, and the important factors in bureaucratic efficiency and productivity are 'such and such'. Can you put those effects in this?" Or, "What happens to the headcount target projections if internal transfers and retraining are used to help deal with skill mix problems?" It is desired that the simulation at this phase instill enthusiasm and elicit new, more comprehensive, and better conceptual models from management.

Consequently, the ithink model in Phase I is not meant be a stand alone, self-explanatory "flight simulator." For those familiar with the ithink interface development environment, the created simulation has a modest interface in the mapping layer comprised of access to inputs, graphs, and switches to turn off and on the various feedback loops. Most of the discussion material presented in this report is also included in the mapping layer via text and graphic boxes. The mapping layer is not used to initiate the manager to the modeling concepts (that will be done in the one-on-one meetings), but rather it serves to provide mental reminders to managers that may decide to experiment with the simulation privately after the meetings.

This report discusses the conceptual model, simulation results, and general conclusions that will be discussed with managers during the one-on-one meetings to be conducted during Phase I. 


\section{CONCEPTUAL MODEL}

The conceptual model of the simulation is shown in Figure 1. It is not meant to be a comprehensive model of personnel management, but rather a vehicle to gain some generic understanding about the staffing problem. Referring to Fig. 1, a company forecasts its future headcount needs based upon projected business conditions. Sometimes hiring and laying off are the mechanisms used to achieve the scheduled decreases and/or increases in manpower. Reducing the gap between targeted and actual headcount through these traditional means are shown by the New Hires and Layoffs loops that flow from the Gap, to Actual Headcount, and back to the Gap. Both of these loops are balanced, meaning hiring and laying off strive to maintain the Gap at a zero level. The label "B" means a loop has a balancing effect upon the Gap. Delays in actually executing hiring and layoff decisions are included in the model and are indicated by the hash marks over the corresponding lines flowing from the Gap. It is assumed that one fourth of a year is required by the company to prepare for executing layoffs and that half a year is required to get a new hire in the door.

Hiring and laying off may have secondary influences that impact the productivity of a workforce. For example, layoffs can decrease morale, which decreases productivity, which in turn means that more employees will be needed to accomplish the same amount of work planned for the original headcount target. Consequently, the real issue becomes reducing the gap between Actual Headcount and the Effective Headcount Target (the Baseline Headcount Target adjusted for changes in Productivity).

Based on the above model, Layoffs always have a balancing effect upon the Gap. This can be seen by following the flow of relationships. If the Gap is less than zero, layoffs will occur, which decreases Morale, decreasing Productivity, and raising the Effective Headcount Target, which ends up closing the Gap. In other words, the Gap going negative results in the Gap returning back to zero via the Layoff/Productivity mechanism. The same can be seen from the Layoff/Attrition loop if a relationship trace is performed. Consequently, all the Layoff loops are labeled "B." The hash marks on the flow from Layoffs to Morale indicate a delay for the influence to disappear. It is assumed that it takes 2 years for employees to "forget" past layoffs. The three time delays (hiring, laying off, and "forgetting") are inputs in the ithink simulation and are changeable by the manager via the mapping layer.

A reinforcing loop, on the other hand, causes the Gap to widen. Our model above has only one such loop, that corresponding to Bureaucratic Inefficiency. Organizational slack (functional resources being wasted) and barriers to communication can increase as the size of a company increases. Bureaucratic Inefficiency is the term given in this model to such a decrease in efficiency. Following the relationship trace, a Gap greater than zero results in hiring, which in turn increases the Actual Headcount, increasing the Bureaucratic Inefficiency, decreasing Productivity, increasing the Effective Headcount Target, which finally ends up in the Gap increasing. Thus, a Gap greater than zero results in the Gap getting even greater via the Bureaucratic Inefficiency feedback loop. The label "R" signifies that this loop has such a reinforcing effect. 


\section{RESULTS}

\section{Invoking a Step Change}

Figures $2-7$ show the response of the system to a downward step change of $10 \%$ in the target headcount when enforcing different combinations of the feedback relationships and independent variables. The time frame used was years, beginning in the year 2000. However, one can think in terms of any generic time period without incurring any loss of understanding. Figure 2 corresponds to the case when only hiring and laying off are used to maintain the Gap at a value of zero. The productivity feedback loops and attrition were deactivated for this run. One can see that the actual headcount smoothly and quickly approaches the new target. The delay between the occurrence of the step change and the initial drop in the actual headcount is because of the assumed 0.25 -year. This graph would suggest that the system could adjust to headcount changes relatively easily.

Fig. 3 shows what happens when the bureaucracy feedback is introduced. Because the step change results in a lower target, the bureaucratic efficiency increases, causing the target headcount to drop even further. The headcount curves converge at a value below the level introduced by the step change itself. Consequently, the influence of bureaucratic efficiency results in a qualitative change in the shape of the target headcount curve.

Figure 4 shows the results when only the morale feedback is introduced (attrition and the bureaucratic efficiency feedback are turned off). It is obvious that morale introduces qualitative changes to the headcount curves. Oscillations result because as layoffs occur trying to approach the lower step value, productivity goes down. This causes the target headcount to spike back up. The target headcount gradually falls back down, approaching the lower value imposed by the step change as the layoffs are "forgotten" and morale is restored. Notice that the time frame to converge on the lower step value is now on the order of decades rather than just a few years. Notice that the target and actual headcount curves are out of phase because of the assumed hire $(0.5$ yr) and layoff ( $0.25 \mathrm{yr})$ time delays.

Both the bureaucratic and morale feedbacks were included for the results shown in Figure 5. One can quickly see that the shape of the curves incorporate the cumulative effect of both feedbacks; there is the reduction in final headcount value because of the bureaucracy feedback, and the oscillation and extended convergence result from the influence of morale.

Attrition is an example of a continuous flow. A baseline annual attrition of 5\% of the workforce was added to the dynamics shown in Figure 6, so this simulation had all the model elements. One qualitative and two quantitative changes are noticeable. First the qualitative change - oscillation occurs before the step change. Attrition causes a reduction of employees from the very beginning, which in turn increases the bureaucratic efficiency. Both of these influences cause the target headcount to drop slightly. The hiring that occurs trying to compensate for the attrition decreases the bureaucratic efficiency, causing the target level to go back up. Consequently, the curves are not straight before the step change is introduced.

The two qualitative changes are: 1) the oscillations are dampened appreciably because less layoffs (and hence, there is a weaker influence of the morale factor) are required to reach the post-step-change target value due to contribution of natural attrition to the employee reduction; and 2) the time required for convergence is appreciably less than on Fig. 5, again because there is less negative morale carryover from layoffs.

The simulation shown in Figure 7 has the complete set of model variables as the previous figure, but the step change is upward rather than downward. Notice the absence of the post-step-change oscillation and extended convergence. The reason is because hiring is used to close the Gap with this step change rather than 
layoffs, so the morale factor isn't a player in this case. Consequently, the direction of the externally induced change in the target headcount is an important factor in the qualitative shape of the curves.

\section{Impact on Effectiveness of Target Schedule}

Figure 8 shows the effectiveness of a workforce whose size follows a sample 22-year target schedule. The absolute values of the headcount numbers represented in the sample target schedule are not related to actual projections, but the general oscillatory behavior is. For the simulation shown in Fig. 8, the productivity feedback was not tied back to the target. Referring back to Fig. 1, it is as if the relationship between Productivity and Effective Headcount Target did not exist. Even though the feedback was decoupled, Productivity is still being measured. This allows us to see how effective the workforce would be if the target schedule was adhered to.

Notice that the effectiveness plateaus at $60 \%$ in the beginning; that is because the default response function for bureaucratic inefficiency is constant at 0.6 after reaching twice the original manpower.

Effectiveness drops later, however, once the strength of the morale factor from layoffs comes into play.

Effectiveness increases in the later years because the demoralizing influence of the previous layoffs is diminished ("forgotten"). However, the effectiveness is still limited to $60 \%$ because of the bureaucratic factor resulting from the back-end hires.

Qualitatively, there are two main insights here. First, one can discern the impact of the factors modeled upon the effectiveness of his/her scheduled target employment levels. In this case, one can see that the hiring/laying off sequence of implementing the target schedule will have appreciable detrimental consequence upon the effectiveness of the workforce. One should be more concerned with the direction of impact (beneficial or detrimental) rather than the quantitative value. In this case, it would not be wise to assign truth to the "fact" that effectiveness will approach a lowly 15\% value around 2011. The insight, rather, is that a layoff segment on the heals of a hiring spree will dramatically impact the workforce's effectiveness, which in turn decreases the business' chance of implementing its competitive strategy.

The second qualitative insight is that limits in one's response functions for feedback variables may cause plateaus and limits in the dependent variables. One needs to be sure that one's characterization of variable relationships agrees with one's qualitative perception of the real system. In this case, one needs to determine whether or not the $60 \%$ front-end plateau and back-end limit is rational and representative of one's perception of reality.

Consequently, the benefit of decoupling feedback is that it allows one to look at intermediate factors and scrutinize one's response functions (the input relationships). In this case, the intermediate factor is effectiveness. After noticing it's dramatic drop in the valley of layoffs, its front-end plateau, and its back-end limit, the decision-maker should confirm that these characteristics agree with her expectations of effectiveness based on her perception of reality. If there is disagreement between the simulation and expectations, then it is recommended that one change the response functions and/or his perception of reality.

\section{Effective Schedule}

For the simulation run shown in Figure 9, the productivity feedback was reconnected - the relationship between Productivity and Effective Headcount Target shown in Fig. 1 was enforced. This essentially allows us to see what headcount at $100 \%$ effectiveness is required to achieve the same work as the target headcount 
originally scheduled. In other words, the Effective Target Headcount curve in Fig. 9 represents the employee level required to achieve the same work planned for the original target headcount schedule.

One can see that the effective headcount never goes below the original target. That is because the bureaucratic inefficiency response lowers efficiency when hiring, and the negative morale response is stronger than the positive bureaucratic response when laying off. Consequently, all feedbacks result in a decrease of effectiveness. In this case, the quantitative characteristics of the planned schedule are impossible to achieve if all of the planned work is to be accomplished. 


\section{CONCLUSIONS}

The results are summarized and generalized in Table 1. The particular elements of the model used in this simulation are not the focus of this learning exercise. The "Generic" columns offer the "meat" because they are most likely applicable to anyone's personal staffing model regardless of what the particular feedback factors and continuous flows may be. The six qualitative and three quantitative generic insights listed in Table I are not presented as revolutionary thought - to the contrary, they should be familiar to those knowledgeable of system dynamics or computer/instrument process control. Their potential usefulness to developing staffing strategies is the point being stressed, not any potential theoretical novelty.

Three overarching assertions follow from Table 1:

1) the presence of multiple feedbacks, time delays, and continuous flows introduce instability into a personnel system that complicates the management of staffing levels. Many times "soft" variables, such as morale, productivity, and efficiency are the sources of such influences;

2) such influences can be successfully modeled. In the case of this particular model, for example, the qualitative impact of a strategy based on hiring and laying off is assessed; and

3) rather than depend upon only simple, quantitative assessments of staffing decisions (i.e., Fig. 2), it is advantageous to include influences from the "soft" factors (i.e., Figs. 8 and 9). 


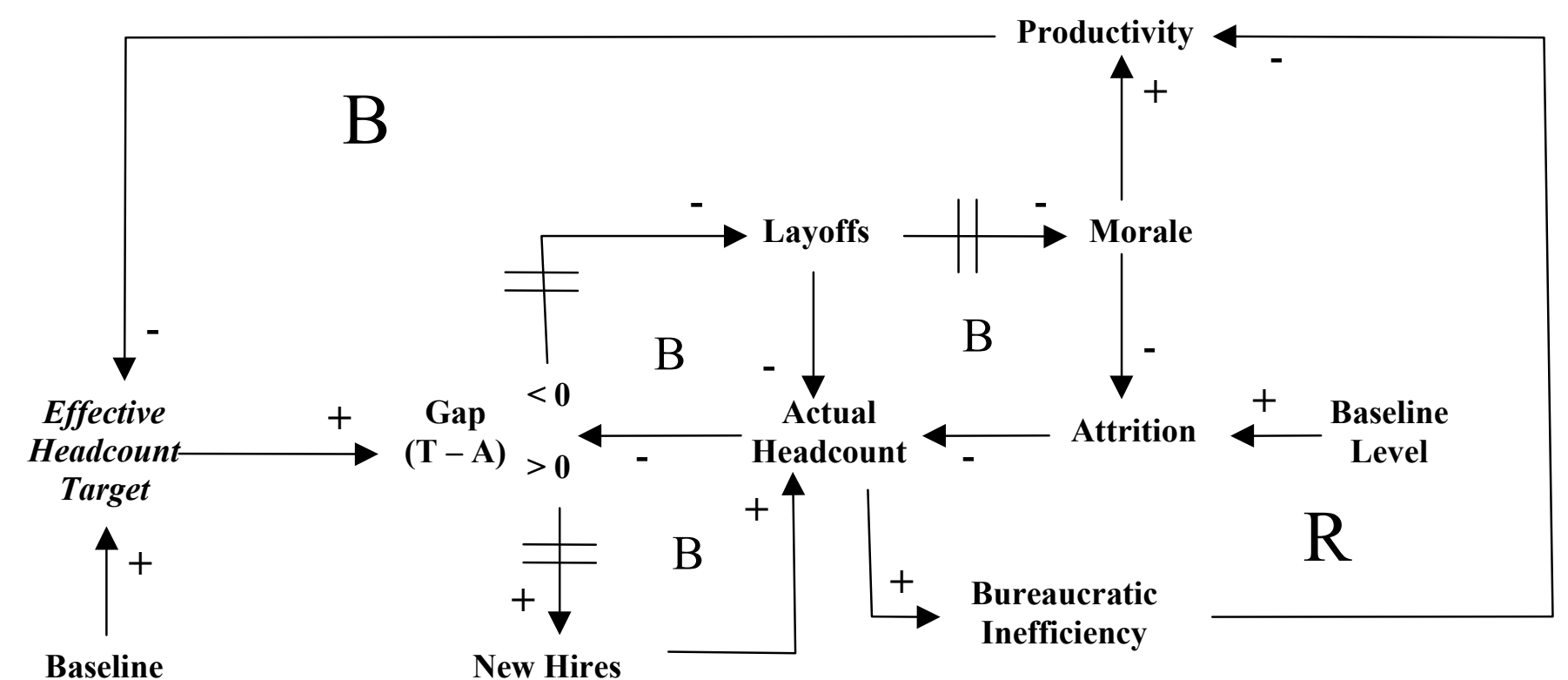

Headcount

Target

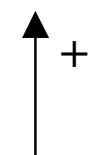

Attractiveness of

Projected Business

Conditions

Figure 1. Basic Conceptual Staffing Model. 


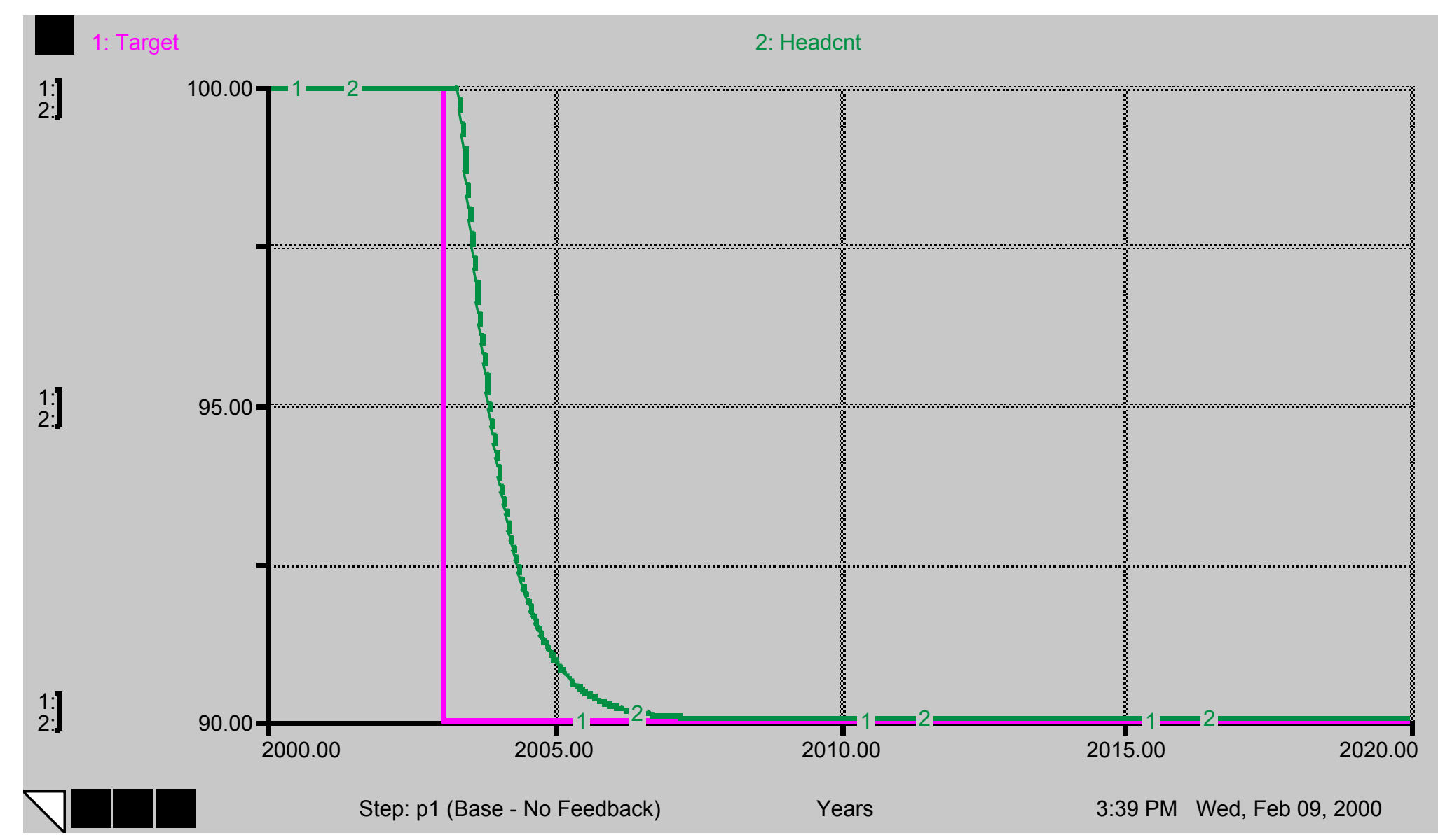

Figure 2. Response With No Feedback Added (Only Hiring \& Laying Off Used To Push Actual Towards Target). 


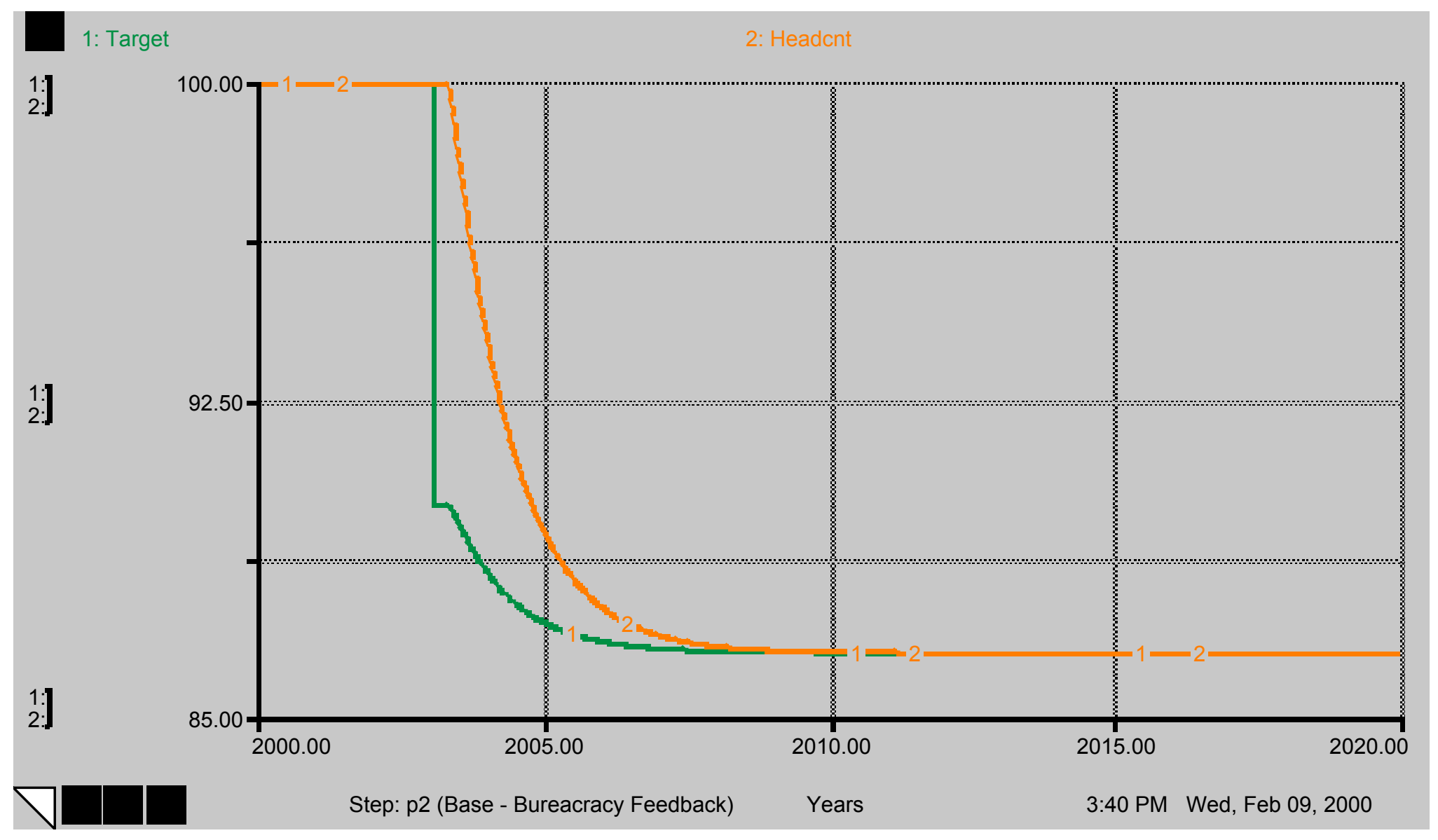

Figure 3. Response With Only Bureaucracy Feedback Added. 


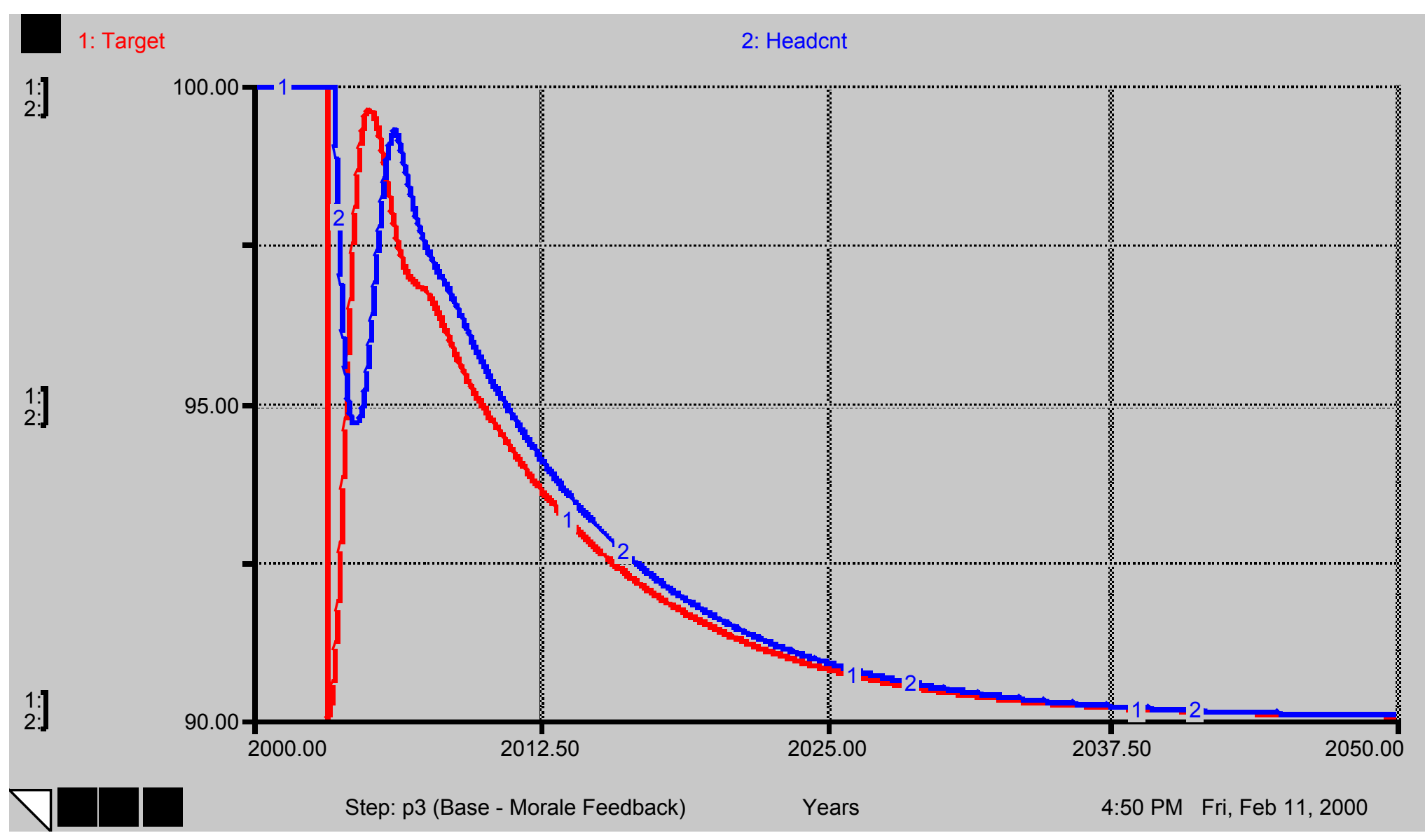

Figure 4. Response With Only Morale Feedback Added. 


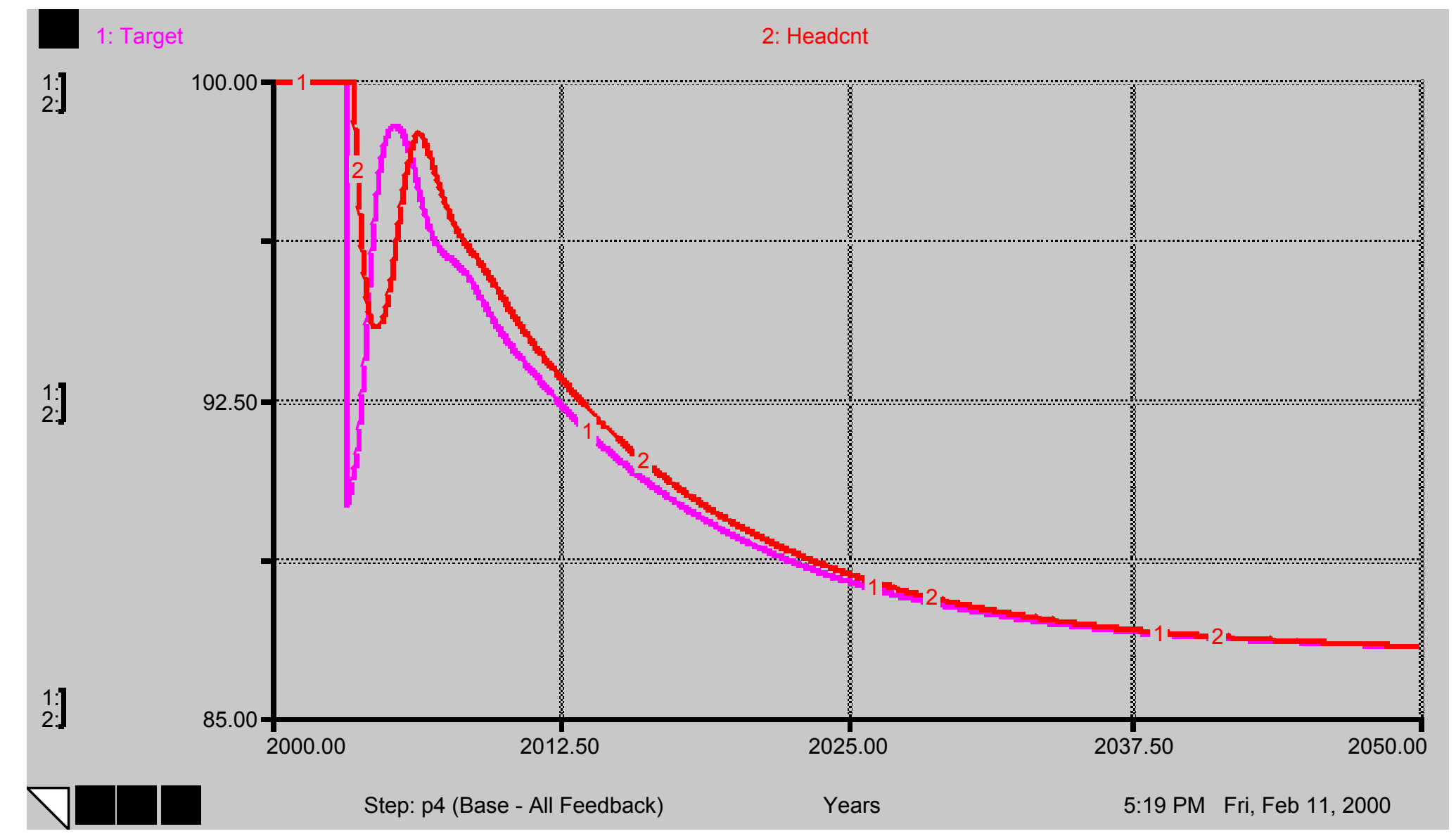

Figure 5. Response With All Feedback Added. 


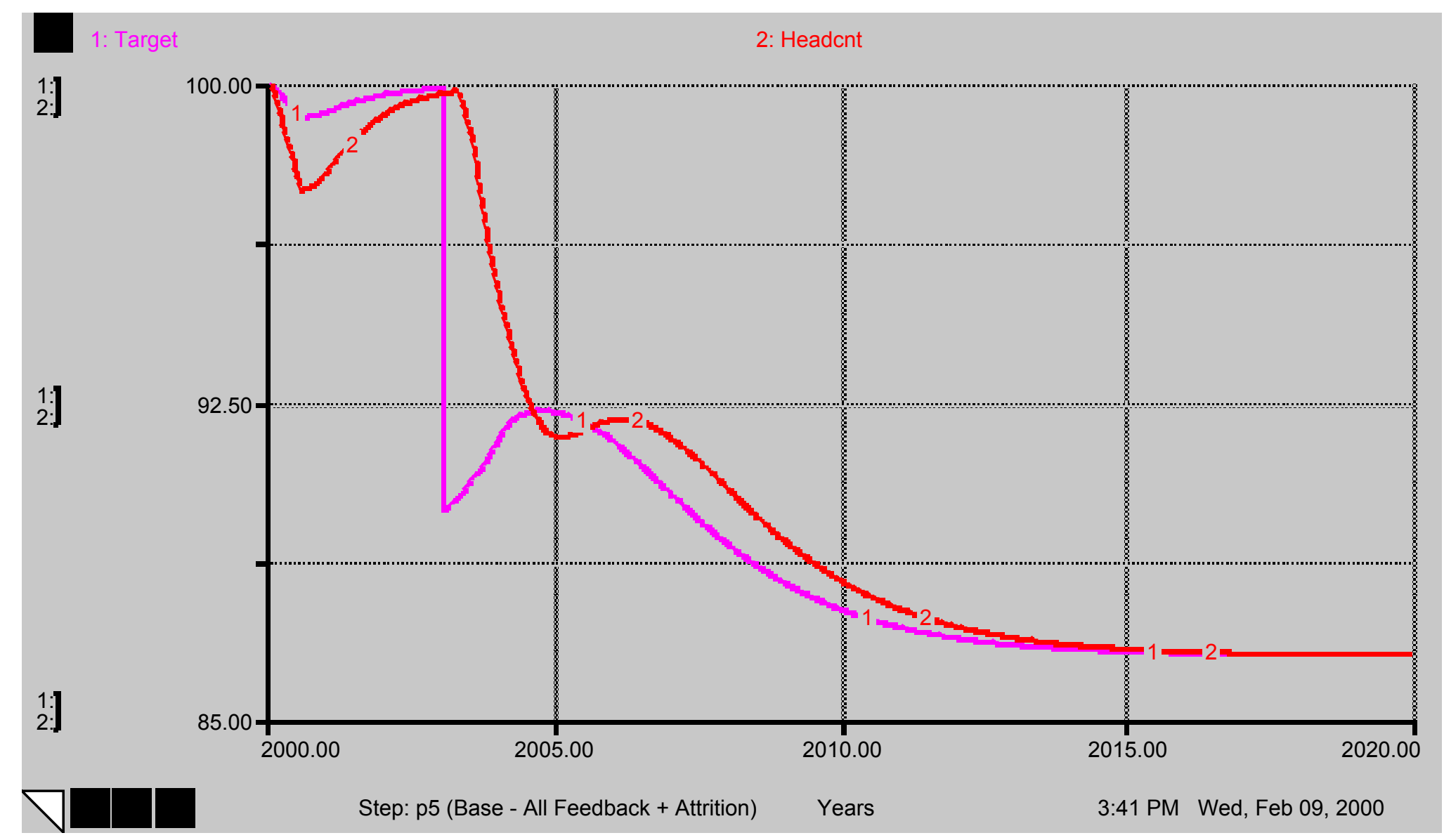

Figure 6. Response With All Feedback And Attrition (Downward Step Change). 


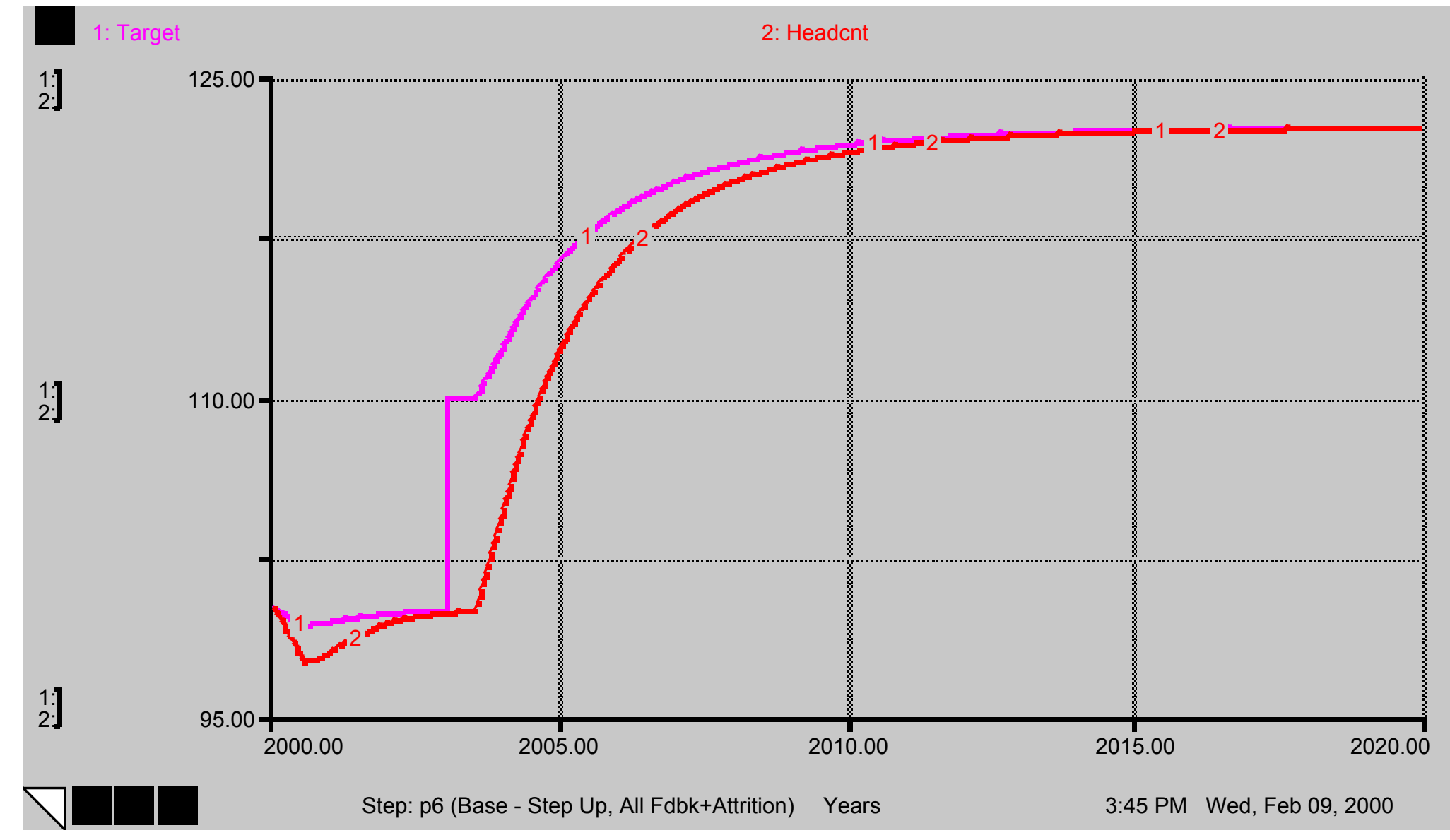

Figure 7. Response With All Feedback And Attrition (Upward Step Change). 


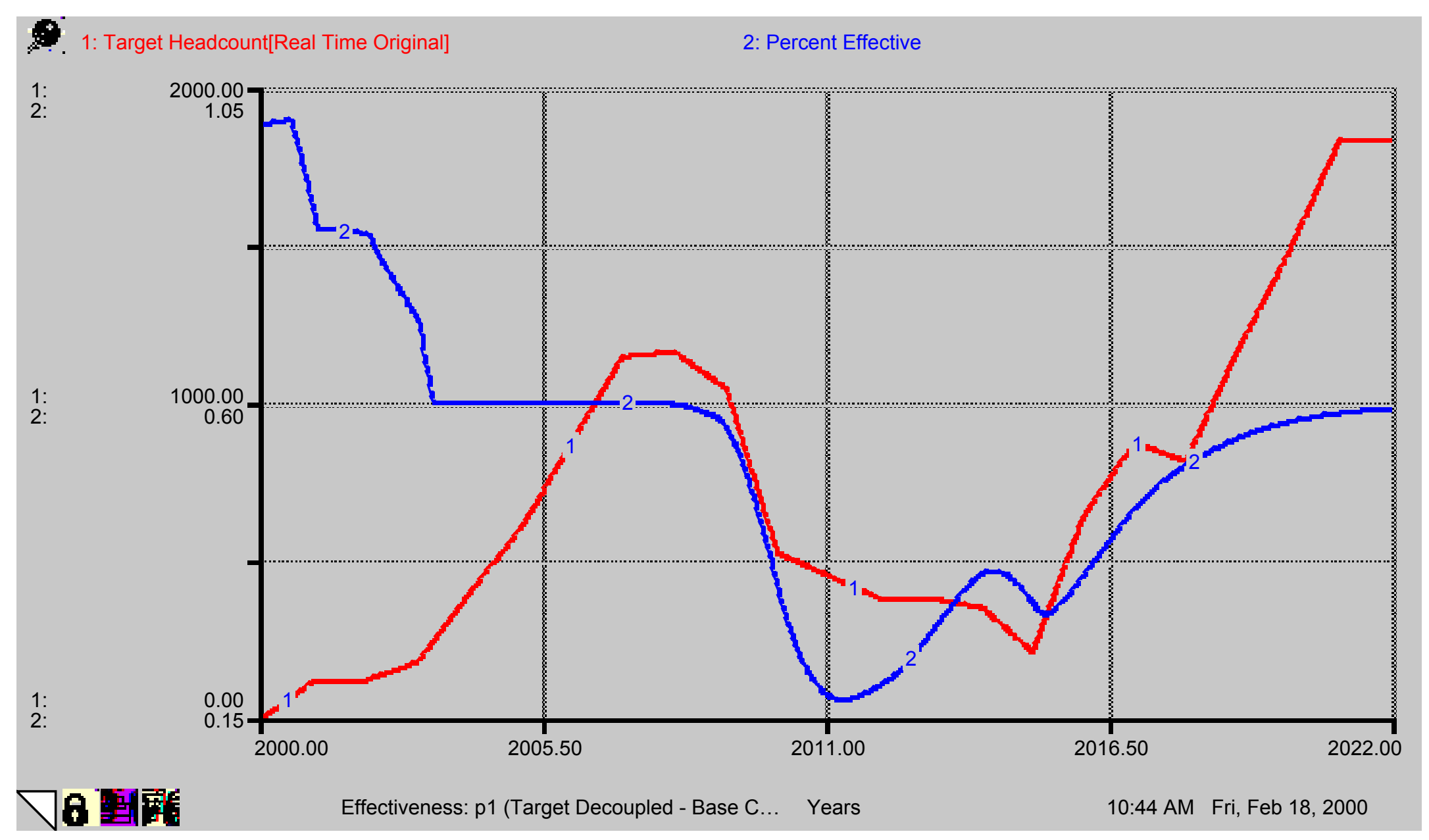

Figure 8. Target Decoupled From Productivity Feedback (Fluctuating Target). 


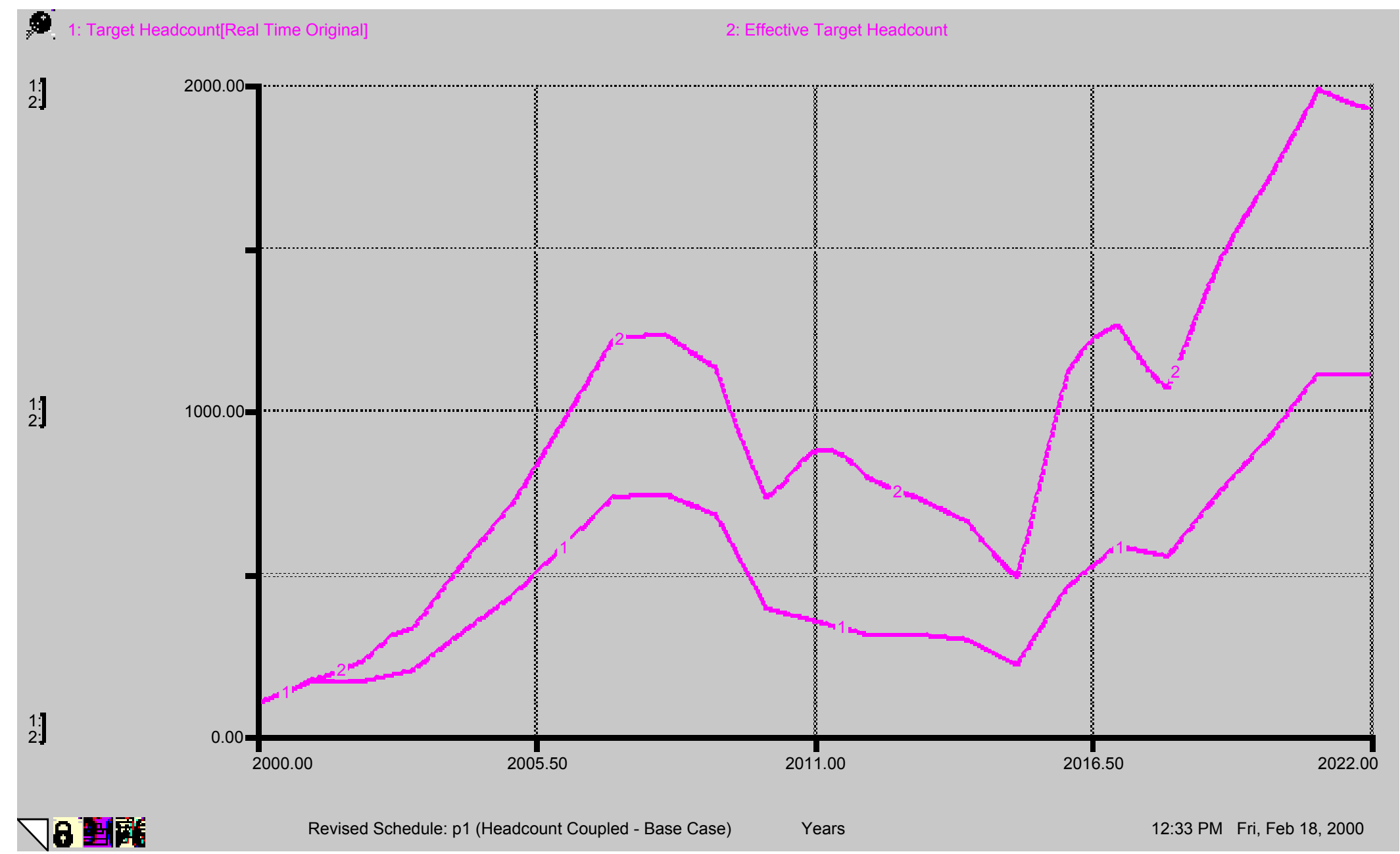

Figure 9. Modified Target To Account For Productivity Feedback. 


\begin{tabular}{|c|c|c|c|c|}
\hline \multirow{2}{*}{ REFERENCE } & \multicolumn{2}{|c|}{ QUALITATIVE INSIGHTS } & \multicolumn{2}{|c|}{ QUANTITATIVE INSIGHTS } \\
\hline & Generic & Specific to Model & Generic & Specific to Model \\
\hline $\begin{array}{l}\text { Step change down with } \\
\text { only hiring and laying off } \\
\text { (no secondary feedbacks } \\
\text { nor attrition) - Fig. } 2\end{array}$ & $\begin{array}{l}\text { In the absence of continuous flows (such } \\
\text { as attrition) and multiple feedbacks, a } \\
\text { system can smoothly respond to a step } \\
\text { point change }\end{array}$ & $\begin{array}{l}\text { Actual headcount quickly approaches } \\
\text { the new lower target }\end{array}$ & & \\
\hline $\begin{array}{l}\text { Step change with } \\
\text { bureaucratic efficiency } \\
\text { feedback - Fig. } 3\end{array}$ & $\begin{array}{l}\text { A reinforcing feedback causes the target } \\
\text { to continually increase or decrease }\end{array}$ & $\begin{array}{l}\text { Causes the steady-state target to be } \\
\text { lower than the step-down target and } \\
\text { higher than the step-up target. }\end{array}$ & & \\
\hline $\begin{array}{l}\text { Step change down with } \\
\text { morale feedback - Fig. } 4\end{array}$ & $\begin{array}{l}\text { Balancing feedback can introduce } \\
\text { oscillations when system tries to respond } \\
\text { to a change } \\
\text { Process delays can cause actuals to be out } \\
\text { of phase with targets }\end{array}$ & $\begin{array}{l}\text { Causes both hiring and laying off } \\
\text { having to be used trying to achieve } \\
\text { steady state, which introduces } \\
\text { oscillations. The hiring and laying off } \\
\text { delay times add to the instability. }\end{array}$ & $\begin{array}{l}\text { Balancing feedback increases } \\
\text { time required to regain stability } \\
\text { after a change is introduced into } \\
\text { the system }\end{array}$ & $\begin{array}{l}\text { Time for convergence extends } \\
\text { from a few years to decades }\end{array}$ \\
\hline $\begin{array}{l}\text { Step change down with } \\
\text { all feedback and attrition } \\
\text { - Fig. } 6\end{array}$ & $\begin{array}{l}\text { In the presence of multiple feedbacks and } \\
\text { time delays, a continuous flow (in or out) } \\
\text { introduces oscillation without a change } \\
\text { externally imposed upon the system }\end{array}$ & $\begin{array}{l}\text { The continual outflow of employees } \\
\text { from attrition introduces oscillation } \\
\text { before the step change occurs }\end{array}$ & $\begin{array}{l}\text { In the presence of balancing } \\
\text { feedback and time delays, a } \\
\text { continuous flow (in or out) will } \\
\text { dampen the oscillations and } \\
\text { speed the convergence if the } \\
\text { introduced change is in the same } \\
\text { direction as the continuous flow }\end{array}$ & $\begin{array}{l}\text { Less layoffs are required, so } \\
\text { weaker influence from morale } \\
\text { factor. This results in } \\
\text { dampened oscillations and } \\
\text { quicker convergence. }\end{array}$ \\
\hline $\begin{array}{l}\text { Step change up with all } \\
\text { feedback and attrition - } \\
\text { Fig. } 7\end{array}$ & $\begin{array}{l}\text { The direction of the change to an } \\
\text { independent variable can be an important } \\
\text { factor in how the system responds }\end{array}$ & $\begin{array}{l}\text { The influence of morale is absent } \\
\text { because hiring, rather than laying off, } \\
\text { is the process used to achieve stability. } \\
\text { There is neither post-step-change } \\
\text { oscillation nor extended convergence. }\end{array}$ & & \\
\hline $\begin{array}{l}\text { Effectiveness of target } \\
\text { schedule - Fig. } 8\end{array}$ & $\begin{array}{l}\text { Limits in one's response functions for } \\
\text { feedback variables may cause plateaus } \\
\text { and limits in the dependent variables. } \\
\text { One needs to validate that one's } \\
\text { characterization of variable relationships } \\
\text { agrees with one's qualitative perception } \\
\text { of the real system. }\end{array}$ & $\begin{array}{l}\text { The response function for bureaucratic } \\
\text { efficiency has a limit value of } 60 \% \text { at a } \\
\text { headcount twice that of the original } \\
\text { headcount. This causes a front-end } \\
\text { plateau and a back-end limit to } \\
\text { employee effectiveness. }\end{array}$ & & \\
\hline $\begin{array}{l}\text { Determine effective } \\
\text { schedule - Fig. } 9\end{array}$ & & & $\begin{array}{l}\text { Ignoring the effects of important } \\
\text { feedbacks, delays, and } \\
\text { continuous flows will result in } \\
\text { system performance much } \\
\text { different than that expected. }\end{array}$ & $\begin{array}{l}\text { The effective headcount target } \\
\text { curve is appreciably higher } \\
\text { than the planned curve. The } \\
\text { quantitative characteristics of } \\
\text { the planned schedule are } \\
\text { impossible to achieve if all the } \\
\text { planned work is to be } \\
\text { accomplished. }\end{array}$ \\
\hline
\end{tabular}

Table 1. Summary Of Simulation Learning. 


\section{ANNOTATED BIBLIOGRAPHY}

Flood, Robert L. and Ewart R. Carson, 1993, Dealing With Complexity: An Introduction to the Theory and Application of Systems Science, Second Edition, New York: Plenum Press. Provides excellent explanations of system types, terminology, concepts, and control theory. Discusses how to use a systems approach to solve hard and soft problems. Has a more technical and formal presentation style than the other books listed here.

Morecroft, John D. and John D. Sterman, editors, 1994, Modeling for Learning Organizations, Portland, Oregon: Productivity Press. Provides good perspectives on modeling dynamic, human-based systems. Offers good discussions on building models and the potential of computer simulations to facilitate managerial learning regarding organizational performance and strategy.

Senge, Peter M., 1990, The Fifth Discipline: The Art \& Practice of The Learning Organization, New York: Doubleday/Currency. Focused on the dynamics of human-based systems and using systems thinking to solve soft problems, identifying patterns that control events and determining the most effective levers of change. Excellent explanation of the roles of, and interrelationships between, the system's structure and the personal behavior of individuals in the organization's performance.

Weinberg, Gerald M., 1975, An Introduction to General Systems Thinking, New York: John Wiley \& Sons. A must read for anybody interested in learning about the general laws of systems. Uses examples from many disciplines, is written in layman terms, and the author uses a conversational writing style. It is currently out of print, but it is worth the effort to obtain a used copy. 